\title{
DEVELOPING BUSINESS ENGLISH COMMUNICATION SKILLS AND INTERCULTURAL COMPETENCE: A STUDENT-CENTRED APPROACH
}

\author{
Anabela Simões ${ }^{1}$, Sílvia Ribeiro' ${ }^{1}$, Ana Rita Calvão \\ ${ }^{1}$ ESTGA-CLLC, University of Aveiro (PORTUGAL) \\ ${ }^{2}$ ESTGA, University of Aveiro (PORTUGAL)
}

\begin{abstract}
Communication is the cornerstone of organisational life, either at an internal level or exogenously [1]. As organisations expand internationally, having to interact with transcontinental intermediaries, distinct government agencies and institutions [2] or company foreign representatives, an adequate level of linguistic competence is likely to play an even more significant role in facilitating or hampering any global operation [3].
\end{abstract}

As language and culture go hand in hand, in today's globalised world it is also of paramount importance to develop cultural sensitivity. According to [4], it is not just helpful to business but a recognized essential, since businesses that understand and accommodate individuals from different cultural backgrounds are better equipped to scale and build a better reputation amongst their competitors.

With over 1.5 million speakers worldwide [5], English has become not only the language of science and technology [6] but also the global language of business. The awareness that communicative competence in English is crucial in today's labour market is reflected in the study programme design of the $1^{\text {st }}$ cycle degree in Office Management and Business Communication (OMBC) held at the University of Aveiro (UA), which includes five 60-hour courses of Business English: English Language ( $1^{\text {st }}$ semester), English Translation and Terminology $\left(2^{\text {nd }}\right.$ semester $)$, English Language and Business Communication ( $3^{\text {rd }}$ semester), English Documentation $\left(4^{\text {th }}\right.$ semester), and English Language and Organizational Culture ( $5^{\text {th }}$ semester).

Literature demonstrates that student-centred learning environments, where practical and more realistic assignments can be developed, are likely to be more effective and conducive to a greater level of development of both technical and interpersonal skills [7]. Bearing this view in mind, the present paper aims to describe two project-works developed within two OMBC courses: English Language and Business Communication and English Documentation. In their first assignment $\left(1^{\text {st }}\right.$ semester, 2018/19), students were called to develop research on a country of their choice, analyse it through Hofstede's 6-D model, allocate it to Hall's high-/low-context cultures and identify each country's specific characteristics in terms of business etiquette. The results of their research, whose main purpose was the development of students' intercultural business communication skills, were displayed in poster format and presented to the class, simulating a conference setting. In their second projectwork $\left(2^{\text {nd }}\right.$ semester, 2018/19), those same students were challenged to conduct research on the impact of digital transformation on organizations, one of the topics of their syllabus, and again exhibit their findings in a scientific poster - this time not having the classroom as venue, but in the context of a conference organized at the UA. After following the regular procedures of an abstract and poster submission, selected students have the opportunity to present their assignment in a real scientific event, to their peers and to conference participants.

In addition to the detailed description of these project-works, this paper also aims to present the results of a survey on students' perception of the activities. The gathered data indicates that both technical and interpersonal competences were successfully addressed.

Keywords: language teaching strategies, English for specific purposes, business communication, communicative competence, intercultural sensitivity.

\section{INTRODUCTION}

The undergraduate academic degree in Office Management and Business Communication (OMBC), awarded by the Higher School of Technology and Management of the University of Aveiro (ESTGA$\mathrm{UA}$ ), aims at training qualified professionals capable of assisting and providing support to board or 
administrations members of public and private companies or agencies, at both national and international levels.

Since its adequation to the Bologna Process, in academic year 2007/2008, the course structure of this three-year full-time degree (180 ECTS) covers different disciplinary areas such as Languages (66 ECTS), Secretarial Studies and Business Communication (54 ECTS), Social Sciences (18 ECTS), Information Technology (12 ECTS), among others. Due to its multi- and interdisciplinary training, graduates are prepared to manage complex communication flows, contributing thus to the management process and development of organisations.

With over 1.5 million speakers worldwide [5], English has become not only the language of science and technology [6] but also the global language of business; according to [8], more and more multinational companies are defining English as their common corporate language with the aim of facilitating communication and performance across geographically diverse functions and business ventures. Aware of this fact, as well as of the importance of mastering other foreign languages in an ever more global and competitive labour market, the study programme in OMBC includes nine 60-hour Second Language (SL) courses, five in English and four in a second foreign language, which can be French, German or Spanish, according to the students' preferences (see Table 1). Moreover, in their $6^{\text {th }}$ semester, students have the opportunity to complete an internship in an organisation; during this period, business writing and oral interactions with different stakeholders in one or two of the learned SL are also frequent activities integrated into students' work plans.

Table 1. OBMC course structure: SL for specific purposes

\begin{tabular}{|c|c|c|}
\hline \multirow[t]{2}{*}{$1^{\text {st }}$ YEAR } & $1^{\text {st }}$ semester & $2^{\text {nd }}$ semester \\
\hline & $\begin{array}{ll}\text { - } & \text { English Language } \\
\text { - } & \text { French/German/Spanish for Beginners }\end{array}$ & $\begin{array}{ll}\text { - } & \text { English - Translation Technologies } \\
\text { - } & \text { French/German/Spanish Language } \\
\end{array}$ \\
\hline \multirow[t]{2}{*}{$2^{\text {nd }}$ YEAR } & $3^{\text {rd }}$ semester & $4^{\text {th }}$ semester \\
\hline & $\begin{array}{l}\text { - English Language and Business } \\
\text { Communication } \\
\text { - } \quad \text { French/German/Spanish - Customer } \\
\text { Relations and Hospitality }\end{array}$ & $\begin{array}{l}\text { - } \quad \text { English Documentation } \\
\text { - } \quad \text { Technical French/German/Spanish }\end{array}$ \\
\hline \multirow[t]{2}{*}{$3^{\text {rd }}$ YEAR } & $5^{\text {th }}$ semester & $6^{\text {th }}$ semester \\
\hline & $\begin{array}{l}\text { - English Language and Organisational } \\
\text { Culture }\end{array}$ & (Internship) \\
\hline
\end{tabular}

In today's globalised world, where cultural differences can affect the efficiency of processes and the development of a business, it is also of paramount importance to develop cultural sensitivity, i.e., the ability to relate to the "other". According to [4], awareness of how cultural differences can affect business communication is not just helpful, it's essential. In fact, organisations that understand and accommodate individuals from different cultural backgrounds are better equipped to scale and build a better reputation amongst such a competitive global market.

Major changes have taken place in European higher education over the past years. One of the most significant developments is the shift in the learning paradigm: the evolution from traditional, teachercentred instructional models to learner-centred approaches, which, according to several studies, tend to be more effective and conducive to a higher level of competences development [7]. Competences, which the European Commission defines as "the proven ability to use knowledge, skills and personal, social and/or methodological abilities, in work or study situations and in professional and personal development" [9], can be divided into two distinct categories: the cognitive and technical competences, also commonly known as "hard skills", and the so-called "soft skills", i.e., the combination of interpersonal and social skills.

The objective of the present work is, on the one hand, to present two student-centred experiments based on project-works that seek to integrate knowing and doing while developing students' organisation, cooperation and sense of agency and responsibility, among other aspects. On the other hand, this paper aims at assessing the effectiveness of these experiments in terms of concrete outputs and competence development. 


\section{CONTEXT}

In the 2018/2019 edition, OMBC $2^{\text {nd }}$ year English learners were challenged to develop two different project-works, one in each semester. Project 1 was developed within the curricular unit (CU) English Language and Business Communication (ELBC) and Project 2 was carried out within the course English Documentation (ED).

ELBC aims, on the one hand, at consolidating and improving language skills that were previously acquired, and, on the other hand, at promoting activities that are similar to students' future professional contexts, according to the level B2 of the Common European Framework of Reference for Languages (CEFR). By the end of this CU, which is built around four main sections -1 . Communication; 2. Intercultural communication; 3. Intercultural sensitivity in business communication; 4. Business communication: telephoning and socializing (both in general and in cross-cultural contexts) -, students are expected to:

a) describe various types of communication and recognise the contextual variation of the language;

b) produce oral and written texts, consistent and appropriate to different contexts of business communication;

c) identify dysfunctional communicative situations in intercultural contexts;

d) develop research in the field of intercultural communication;

e) present and critically analyse the results of this research;

f) optimise the production of oral and written statements in a business context through the use of online tools.

Similarly to every other SL course taught to OMBC students, ED also aims at consolidating the previously acquired communicative competences and at introducing hands-on activities with application to real work life situations, mostly through task-based and problem-based strategies. By the end of this $\mathrm{CU}$, which is built around three main sections -1 . Technological changes; 2 . Business written communication; 3 . Official and administrative documentation -, students are expected to:

a) recognise the role of functional texts in contexts of communication for specific purposes;

b) correctly apply the procedures inherent to the different stages in the production of administrative and official documentation;

c) plan and prepare, with linguistic and discursive as well as with graphic and formal correctness, appropriate documents to different situations of communication;

d) select the proper tools to produce documentation for specific purposes.

Conducting research is not only an important component for the development of scientific thinking but also a very relevant skill in any business-related context [10]. Considering the broad skillset it requires [11], both proposed activities are, in its nature, research-based projects. The detailed description of the tasks developed within each of these CUs and the obtained results, as well as students' perceptions of the proposed activities, are presented in the following sections.

\section{PRESENTATION OF THE ACTIVITIES}

In the following paragraphs, the project-works developed by OMBC 2nd year students within the CUs English Language and Business Communication (ELBC) and English Documentation (ED) shall be described.

\subsection{Project 1: Profiling national cultures}

The 22 students enrolled in ELBC were asked to work in pairs and conduct research on the cultural specificities of a country of their choice. Afterwards, the findings of their study should be presented in the form of a scientific poster. It should follow the template provided by the teacher, which included the following fields: title, authors' affiliation, abstract, keywords, introduction, main body, conclusion and references (APA $6^{\text {th }}$ edition style).

With the aim of helping students focus their attention on specific aspects of the given theme, each group was given some guidance in terms of relevant topics to research and develop. Table 2 
summarises this information and Fig. 1 showcases the provided template, already in the form of two completed posters. The theoretical framework that supports topics 1.2. and 1.3. - Geert Hofstede's cultural dimensions model and Edward Hall's high and low-context cultural framework - is part of the CU's syllabus and was extensively discussed in class.

Table 2. Profiling national cultures: list of suggested/targeted topics

\section{Country's presentation}

1.1. General info, geographic and demographic data

1.2. Analysis through G. Hofstede's 6-D model

1.3. Allocation to E. Hall's high and low-context cultures

1.4. Major challenges to Portuguese international companies

\section{Business etiquette: most relevant specific characteristics}

- Greetings, introductions and business cards

- Eye-contact, personal space and touch

- Time

- Socialising

- Gift-giving

- Gestures and other nonverbal communication

- Dress and appearance

- Cultural attitudes and behaviours

- Dining and tipping customs

- Conversational customs and manners

\section{Official entities where additional information can be found}

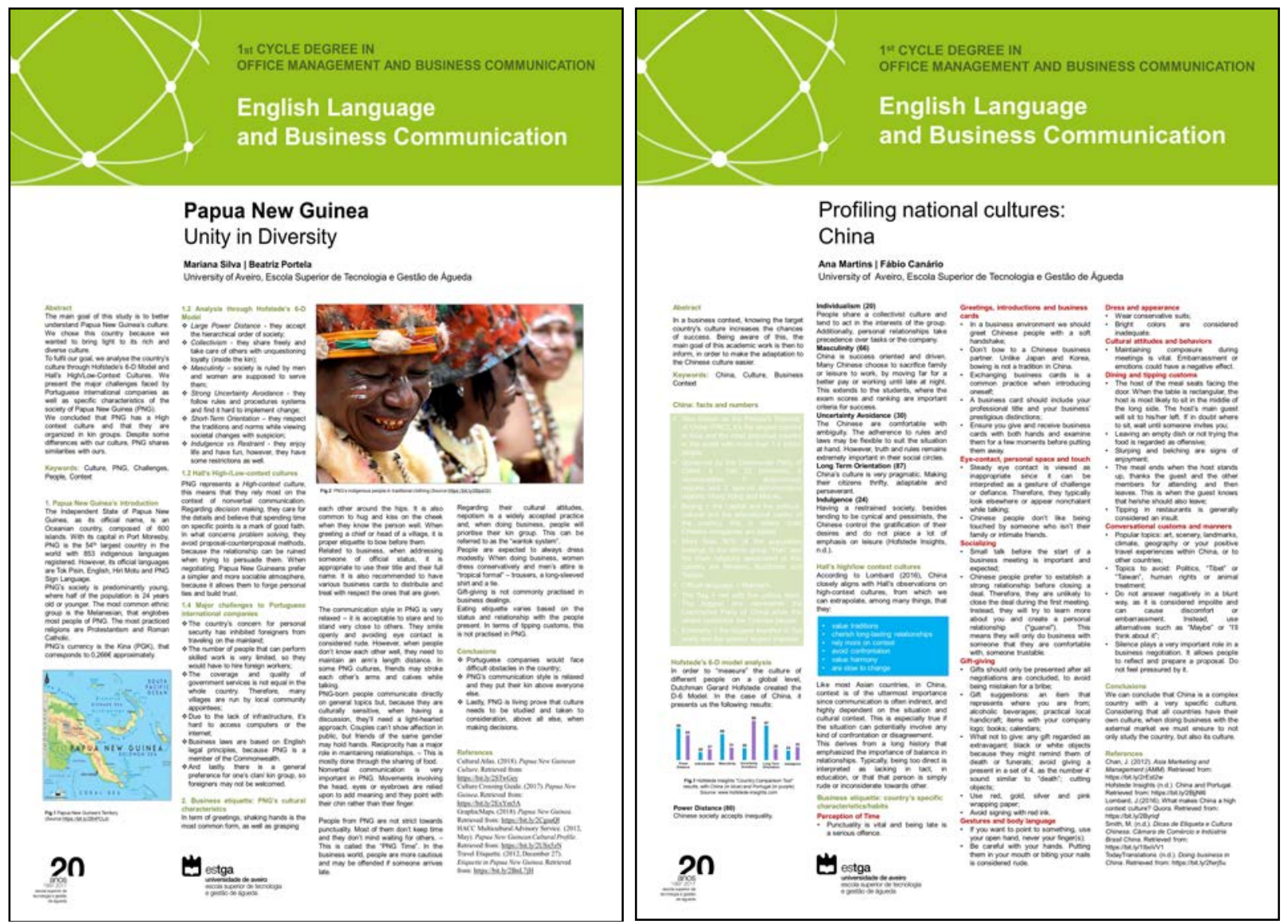

Figure 1. Project 1: examples of submitted posters 
This project, which resulted in 11 research posters that focused on the countries/cultures lined up in Table 3, was developed between September and December 2018. During the semester, additional support and feedback on the on-going work were provided by the teacher.

Table 3. National cultures studied in Project 1

\begin{tabular}{|l|l|}
\hline \hline Group 1 & China \\
\hline Group 2 & Italy \\
\hline Group 3 & Japan \\
\hline Group 4 & Colombia \\
\hline Group 5 & India \\
\hline Group 6 & Germany \\
\hline Group 7 & Thailand \\
\hline Group 8 & Papua New-Guinea \\
\hline Group 9 & Saudi-Arabia \\
\hline Group 10 & Morocco \\
\hline Group 11 & Arab Emirates \\
\hline \hline
\end{tabular}

At the end of the semester, posters were printed and displayed in the classroom. Simulating a conference setting, every group was granted 15 minutes, followed by a period of questions, to present their findings to the class.

A quantitative grade (from 1 to 20 ), which weighted $60 \%$ in the overall grade of the course, was attributed to the project-work (poster + oral presentation). The following partial scores were defined for each criterion:

a) Materials > content and accuracy: 7 points, if poster is fully compliant with the topic, well organised and error-free, with complete, creative and relevant information/perspectives, also if formatting, word limit and references are as defined.

b) Fluency: 4 points, if speech is effortless and smooth, with only rare repetition or self-correction, if topics are fully and appropriately developed, also if the student uses appropriate vocabulary and expresses ideas eloquently.

c) Pronunciation: 4 points, if there are no obvious mispronunciations and when intonation reinforces communication.

d) Accuracy: 3 points, if the student uses a full range of structures naturally and accurately, maybe only with rare minor 'slips' that do not break down communication.

e) Body language: 2 points, if the student maintains eye-contact and is relaxed and engaged.

The score for criterion a) is the same for both group members; the scores for criteria b), c), d) and e) depend on each student's individual performance. Moreover, a table with the adopted criteria was presented to students in their first class and published in the CU's work area of UA's eLearning platform at the beginning of the semester.

\subsection{Project 2: The impact of digital transformation on organisations}

As alluded before, all OMBC language courses are applied to professional contexts, and the English $4^{\text {th }}$ semester CU, English Documentation, is no exception.

The ever more rising prevalence of technology in our lives today, digital transformation, the 4th industrial revolution, and the impact of these technological changes on careers are topics debated within the CU's first unit. Students are, therefore, stimulated to reflect upon how digital transformation has led to changes at both social and economic levels, challenging organisations to rethink their management, communication, and leadership models. How it has also led to the development of digital networks and services, which require adaptation to new business models and forms of relationship with the various publics, flexibility in processes, as well as the adoption of technologies that favour a global and multicultural performance. 
In their second project-work, 20 students were challenged to organize themselves in groups of two or three and conduct research on the impact of digital transformation on organizations, with a special focus on the areas of secretarial studies and business communication. The results of their study should be again displayed in a research poster format, which would account for $20 \%$ of their final grade (no mandatory oral presentation was requested).

This time around, no targeted guidelines were provided by the teacher. Students had to more autonomously develop their own work plan and find the best approach to the proposed theme, which required them to discuss, debate, and negotiate within the group in a more consequential fashion.

Students were motivated to strongly invest in this assignment, since there was a higher stake setting involved: the best assignment(s) would be submitted to a real scientific event, to the Conference "Digital Transformation: Practices, Challenges and Solutions", which will take place at ESTGA-UA, on May 29, 2019. The opportunity to participate and present their work in a real event is more than an enriching extracurricular initiative; due to the inherent sense of purpose underlying the project-work, this initiative also reveals the real-world impact of their academic assignments.

The task resulted in 8 posters, which were assessed in terms of a) Adequacy ( 6 points out of 20, if the text is fully compliant with the topic, is very complete, creative and presents relevant information/perspectives, also if formatting, word limit and referencing are as defined); b) Organisation (4 points out of 20 , if students produce a clear and cohesive text, which is very well organised, with elements of phrase binding, well-defined and organised paragraphs and clear and direct presentation of ideas); c) Language accuracy (10 points out of 20, if students consistently produce a full range of elaborate, correct and appropriate structures).

Three groups, whose assignments were particularly interesting, innovative and well-developed (Table 4), were invited to send their proposals to the organizing committee of the above-mentioned Conference.

Table 4: English Documentation students' participating posters

\begin{tabular}{|l|l|}
\hline \hline Poster 1 & $\begin{array}{l}\text { The future is now. The impact of digital transformation on } \\
\text { business models and corporate communication. }\end{array}$ \\
\hline Poster 2 & $\begin{array}{l}\text { Communicating in a mobile, connected world: the impact } \\
\text { of digital transformation on the University of Aveiro. }\end{array}$ \\
\hline Poster 3 & $\begin{array}{l}\text { AdRA and Prokura: two Portuguese companies on the } \\
\text { path to digital transformation. }\end{array}$ \\
\hline \hline
\end{tabular}

The submitted proposals, which were subject to a blind peer review process by reviewers that are experts in the areas of Secretarial Studies and Business Communication, were unconditionally accepted by the scientific committee. Based on criteria such as originality, relevance and adequacy to the Call for Papers, methodological adequacy and compliance with the defined norms, each proposal received very positive responses from the respective revisors.

Currently, and under the supervision of their ED teacher, students involved in this initiative are preparing the final drafts of their posters, which shall be included in the proceedings eBook and presented to the Conference fellow participants and general public later this month.

\section{STUDENTS' PERCEPTIONS OF THE ACTIVITIES}

After having completed Project-work 2, students were invited to reflect upon the two research activities developed within ELBC ( $\left(1^{\text {st }}\right.$ semester) and ED ( $2^{\text {nd }}$ semester $)$ and answer a short online questionnaire, which was anonymous and included questions related to the development of their competences. Answering the questionnaire was not mandatory and data from the 20 students enrolled in ED was collected.

A Likert-like scale from 1 to 5 was used. Data analysis shows that, on average, students consider the accomplishment of both project-works as being very positive. As can be observed in Fig. 2, cognitive and functional competences are assessed with mean values above 3.9. General vocabulary expansion/enrichment (4.1), academic writing skills (4.05), English communications skills (4.0), and business English terminology (4.0) are, according to students' perception, the mostly developed competences. 


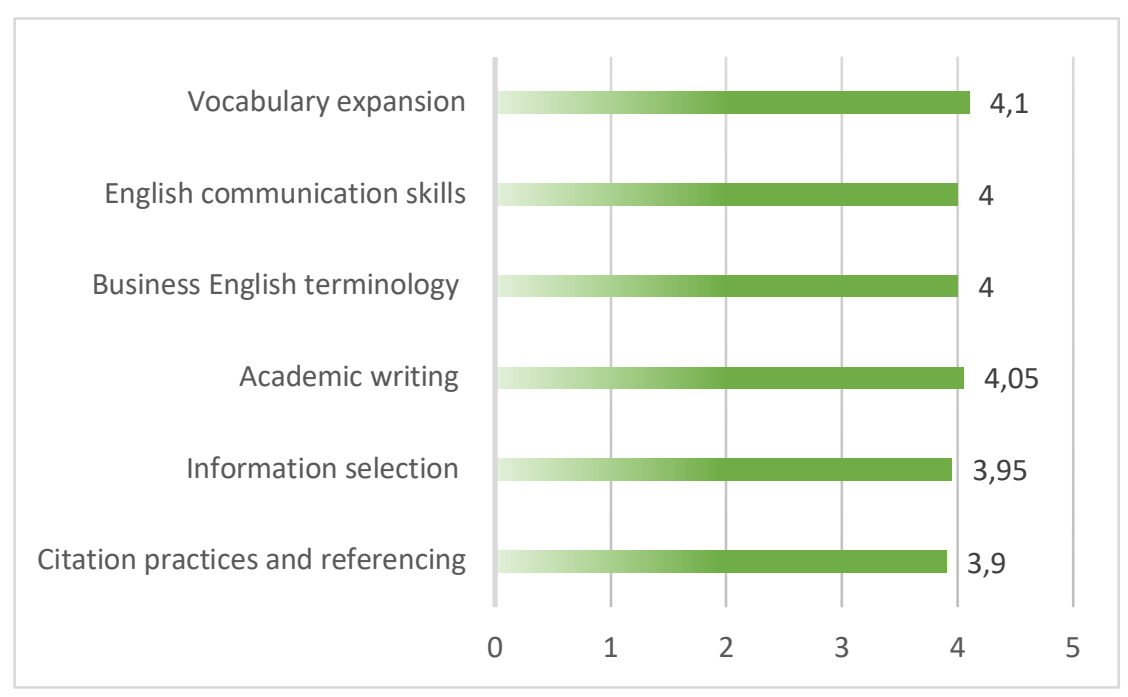

Figure 2. Developed cognitive and functional skills: students' perception (mean values)

As shown in Table 5, Information selection skills (standard-deviation 0.7 ) and Citation practices and referencing (standard-deviation 0.6) are the items were opinions most diverged. Nevertheless, overall results are quite consistent with all minimum and maximum values between 3.0 and 5.0.

Table 5: Cognitive and functional skills: mean, standard-deviation, minimum and maximum, mode and median values

\begin{tabular}{|c||c|c|c|c|c|c|}
\cline { 2 - 6 } & $\begin{array}{c}\text { Vocabulary } \\
\text { expansion }\end{array}$ & $\begin{array}{c}\text { English } \\
\text { communication } \\
\text { skills }\end{array}$ & $\begin{array}{c}\text { Business } \\
\text { English } \\
\text { terminology }\end{array}$ & $\begin{array}{c}\text { Academic } \\
\text { writing skills }\end{array}$ & $\begin{array}{c}\text { Information } \\
\text { selection skills }\end{array}$ & $\begin{array}{c}\text { Citation } \\
\text { practices and } \\
\text { referencing }\end{array}$ \\
\hline \hline Mean & 4.1 & 4.0 & 4.0 & 4.1 & 4.0 & 3.9 \\
\hline $\begin{array}{c}\text { Standard- } \\
\text { deviation }\end{array}$ & 0.5 & 0.5 & 0.5 & 0.5 & 0.7 & 0.6 \\
\hline Minimum & 3.0 & 3.0 & 3.0 & 3.0 & 3.0 & 3.0 \\
\hline Maximum & 5.0 & 5.0 & 5.0 & 5.0 & 5.0 & 5.0 \\
\hline Mode & 4.0 & 4.0 & 4.0 & 4.0 & 4.0 & 4.0 \\
\hline Median & 4.0 & 4.0 & 4.0 & 4.0 & 4.0 & 4.0 \\
\hline \hline
\end{tabular}

These results also demonstrate that, in terms of relevant information selection and citation styles and practices, additional efforts need to be made to help students surmount some of the experienced difficulties (not necessarily within SL courses, though).

With regards to the self-assessment of the developed interpersonal and social skills, teamwork skills (4.05) and autonomy development (4.0) received two of the most positive ratings (see Fig. 3). The most developed/consolidated competence is the item cultural sensitivity (4.5), i.e., awareness of the impact of cultural differences on global business, with $60 \%$ of the respondents giving it a score of 5 . As shown in Table 6, its mode is 5.0, with a standard-deviation of 0.7 . 


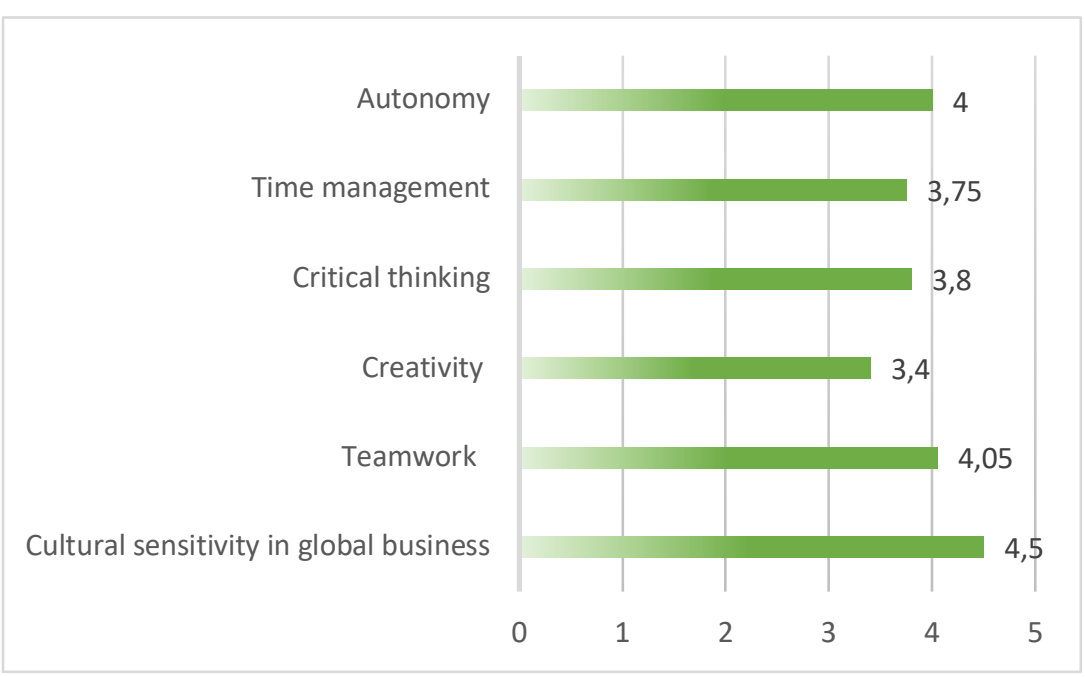

Figure 3. Developed interpersonal and social skills: students' perception (mean values)

A comparison between the two sets of skills reveals a certain discrepancy. Whereas the results obtained for the cognitive and functional skillset are consistent, with relatively low standard-deviations and minimum and maximum values between 3.0 and 5.0, a different pattern can be observed in the development of interpersonal and social skills, in which data is more spread out. This dispersion is particularly noticeable in competences such as creativity (standard-deviation 1.1 and minimum and maximum values between 1.0 and 5.0), development of critical thinking (standard-deviation 0.9 and minimum and maximum values between 1.0 and 5.0), and teamwork skills (standard-deviation 1.0 and minimum and maximum values between 2.0 and 5.0 ).

Table 6: Interpersonal and social skills: mean, standard-deviation, minimum and maximum, mode and median values

\begin{tabular}{|c|c|c|c|c|c|c|}
\cline { 2 - 7 } & Autonomy & $\begin{array}{c}\text { Time } \\
\text { management }\end{array}$ & $\begin{array}{c}\text { Development of } \\
\text { critical thinking }\end{array}$ & Creativity & $\begin{array}{c}\text { Teamwork } \\
\text { skills }\end{array}$ & $\begin{array}{c}\text { Cultural } \\
\text { sensitivity }\end{array}$ \\
\hline \hline Mean & 4.0 & 3.8 & 3.8 & 3.4 & 4.1 & 4.5 \\
\hline $\begin{array}{c}\text { Standard- } \\
\text { deviation }\end{array}$ & 0.7 & 0.8 & 0.9 & 1.1 & 1.0 & 0.7 \\
\hline Minimum & 3.0 & 2.0 & 1.0 & 1.0 & 2.0 & 3.0 \\
\hline Maximum & 5.0 & 5.0 & 5.0 & 5.0 & 5.0 & 5.0 \\
\hline Mode & 4.0 & 4.0 & 4.0 & 4.0 & 4.0 & 5.0 \\
\hline Median & 4.0 & 4.0 & 4.0 & 3.0 & 4.0 & 5.0 \\
\hline \hline
\end{tabular}

The lowest score was attributed to creativity (mean value 3.4 and median 3.0). The teacher's own perception is that students, who weren't yet acquainted with the usually mandatory use of pre-defined poster templates in scientific encounters, didn't quite appreciate the fact they were not allowed to freely use their own preferred styles or colour pallets. Time management (mean value 3.75 and minimum and maximum values between 2.0 and 5.0) also seemed difficult to navigate effectively, which demonstrates that more assignments of this nature are necessary in order to more adequately prepare students for the demands of the current workplace, where not rarely professionals are asked to work under tight deadlines and also strive under stress.

\section{CONCLUSIONS}

Considering the positive products of both projects, as well as students' perceptions of the developed activities, it can be concluded these student-centred activities were effective, with a beneficial impact in terms of academic achievement and personal growth. On the one hand, students' business English skills and intercultural competence were successfully addressed and developed; on the other hand, 
the proposed tasks gave students the opportunity to create a "product" through research, teamwork and collaboration, and then to present it to an audience, which gives real-world relevance for learning and contributes to the development of a broader set of knowledge and competences - namely, communication and interaction skills, organisation skills, problem-solving techniques, or negotiation and conflict resolution skills, which can all be transferred to real-world scenarios. By assuming an active rather than passive role in the learning process, the chance to enter the workforce with experiences in the areas of research, team cooperation, critical thinking or even project management will constitute a significant advantage for these students.

\section{REFERENCES}

[1] M. Kunsch, Gestão Estratégica em Comunicação Organizacional e Relações Públicas. São Paulo: Difusão Editora, 2009.

[2] M.Y. Brannen, R. Piekkari and S. Tietze, "The Multifaceted Role of Language in International Business: Unpacking the Forms, Functions and Features of a Critical Challenge to MNC Theory and Performance" in Language in International Business (M.Y. Brannen and T. Mughan, eds.), pp. 139-162, London: Palgrave Macmillan, 2017.

[3] M.S. Schomaker and S. Zaheer, "The role of language in knowledge transfer to geographically dispersed manufacturing operations", Journal of International Management, no. 20, pp. 55-72, 2014.

[4] J. Landau, Why cultural sensitivity should be a forethought, not an afterthought, Forbes, 17 October, 2018. Retrieved from https://www.forbes.com/sites/forbesnycouncil/2018/10/17/whycultural-sensitivity-should-be-a-forethought-not-an-afterthought/\#3d653fb61b69

[5] R. Lustig, Can English remain the 'world's favourite' language?, BBC News, 23 May, 2018. Retrieved from https://www.bbc.com/news/world-44200901

[6] B. Brock-Utne, "English as the Language of Science and Technology" in Human Rights in Language and STEM Education (Z. Babaci-Wilhite, ed.), pp. 111-128, Rotterdam: Sense Publishers, 2016.

[7] S. Severiens, M. Meeuwisse and M. Born, "Student experience and academic success: comparing a student-centred and a lecture-based course programme", Higher Education, vol. 70, no. 1, pp. 1-17, 2015.

[8] T. Neeley, Global Business Speaks English, Harvard Business Review, May, 2012. Retrieved from https://hbr.org/2012/05/global-business-speaks-english\#comment-section

[9] European Commission, The European Qualifications Framework for Lifelong Learning (EQF). Luxembourg: Office for Official Publications of the European Communities, 2008.

[10] A. B. Hunter, S.L. Laursen and E. Seymour, "Becoming a scientist: The role of undergraduate research in students' cognitive, personal, and professional development", Science Education, no. 91, pp. 36-74, 2007.

[11] D. Lopatto, Science in solution: the impact of undergraduate research on student learning. Tucson: Research Corporation for Science Advancement, 2009. 